
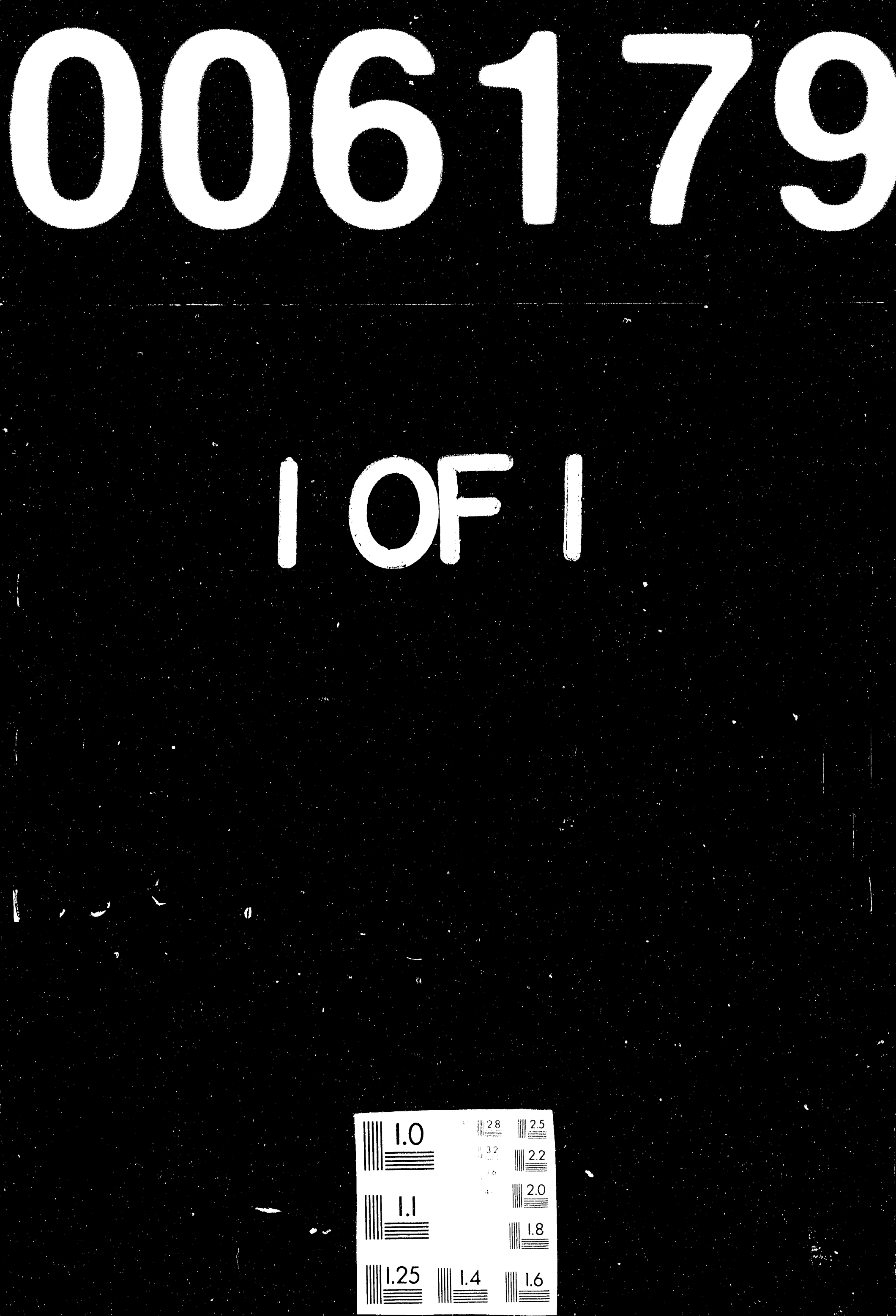

跣: 


\section{EVALUATION OF ENVIRONMENTAL MONITORING THERMOLUMINESCENT DOSIMETER LOCATIONS}

BY

ROBERT KINNISON

DECEMBER 1992

PREPARED BY

REYNOLDS ELECTRICAL \& ENGINEERING CO., INC. POST OFFICE BOX 98521

LAS VEGAS, NV 89193-8521

UNDER CONTRACT NO. DE-AC08-89NV10630 


\begin{abstract}
Geostatistics, particularly kriging, has been used to assess the adequacy of the existing NTS thermoluminescent dosimeter network for determination of environmental exposure levels. (Kriging is a linear estimation method that results in contour plots of both the pattern of the estimated gamma radiation over the area of measurements and also of the standard deviations of the estimated exposure levels.) Even though the network was not designed as an environmental monitoring network, it adequately serves this function in the region of Pahute and Rainier Mesas. The Yucca Flat network is adequate only if a reasonable definition of environmental exposure levels is required; it is not adequate for environmental monitoring in Yucca Flat if a coefficient of variation of 10 percent or less is chosen as the criterion for network design. A revision uf the Yucca Flat network design should be based on a square grid pattern with nodes 5000 feet (about one mile) apart, if a 10 percent coefficient of variation criterion is adopted. There were insufficient data for southern and western sections of the NTS to perform the geostatistical analysis. A very significant finding was that a single network design cannot be used for the entire NTS, because different areas have different variograms. Before any design can be finalized, the NTS management must specify the exposure unit area and coefficient of variation that are to be used as design criteria.
\end{abstract}




\section{TABLE OF CONTENTS}

Page

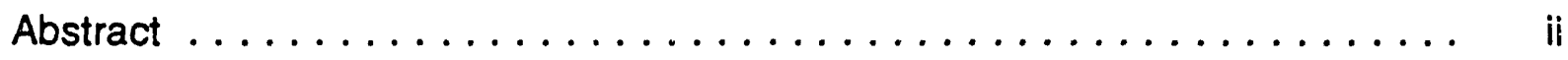

List of Figures $\ldots \ldots \ldots \ldots \ldots \ldots \ldots \ldots \ldots \ldots \ldots \ldots \ldots \ldots$

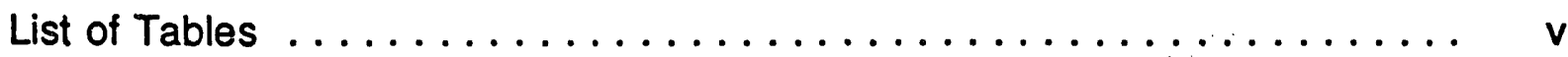

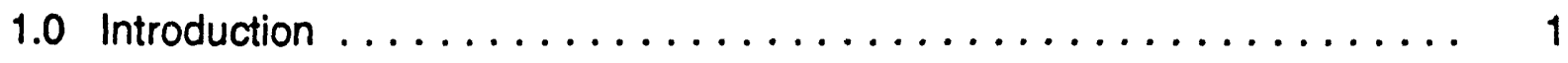

2.0 The Data ............................. 2

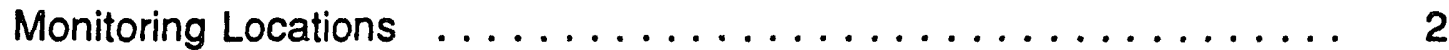

Data Sampling and Screening .................. 6

3.0 Data Analyses . . . . . . . . . . . . . . . . . . . . . . 10

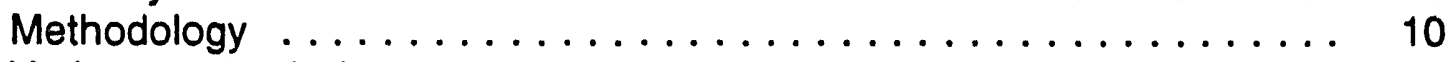

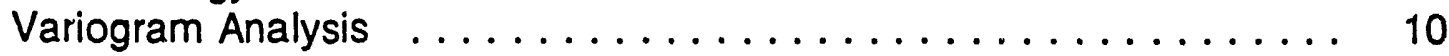

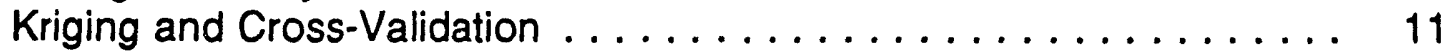

Contouring ............................... 14

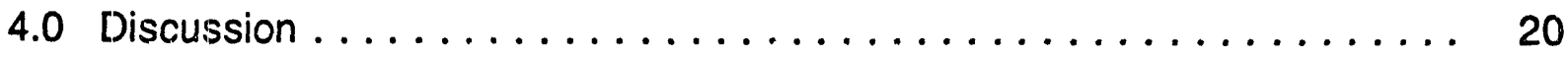

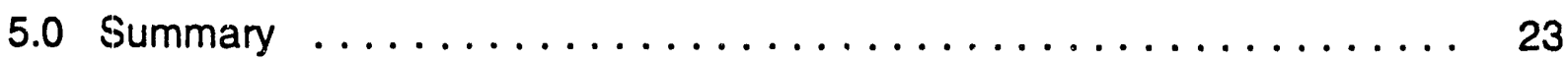

References ............................... 25

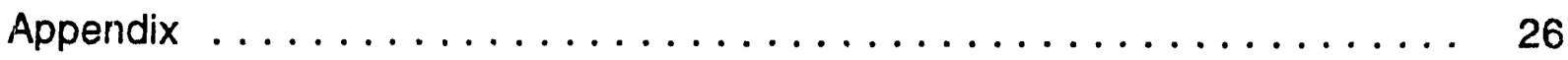

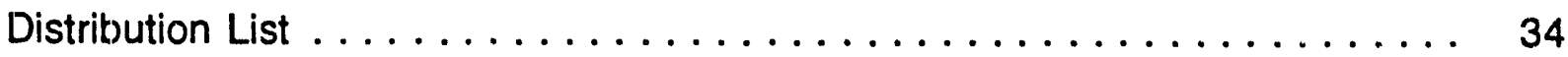




\section{LIST OF FIGURES}

Figure

Page

$1 \quad$ TLD Locations $\ldots \ldots \ldots \ldots \ldots \ldots \ldots \ldots \ldots \ldots \ldots \ldots \ldots \ldots \ldots \ldots$

21990 Pahute Mesa TLD Locations, $m R / y r \ldots \ldots \ldots \ldots \ldots . . \ldots$

$3 \quad 1990$ Yucca Flat TLD Locations, $m R / y r \ldots \ldots \ldots \ldots \ldots$

$4 \quad 1990$ TLD Data $\ldots \ldots \ldots \ldots \ldots \ldots \ldots \ldots \ldots \ldots \ldots \ldots$

$5 \quad$ Pahute Mesa Variogram $\ldots \ldots \ldots \ldots \ldots \ldots \ldots \ldots \ldots \ldots, 12$

$6 \quad$ Kriging Estimates for Yucca Flat $\ldots \ldots \ldots \ldots \ldots \ldots \ldots \ldots$

$7 \quad$ Kriging Standard Deviations for Yucca Flat $\ldots \ldots \ldots \ldots \ldots$

$8 \quad$ Kriging Estimates for Pahute Mesa $\ldots \ldots \ldots \ldots \ldots \ldots . \ldots . . \ldots$

$9 \quad$ Kriging Standard Deviations for Pahute Mesa ........... 19 


\section{LIST OF TABLES}

Table

Page

1990 Data that is Above $250 \mathrm{mR} / \mathrm{yr} \ldots \ldots \ldots \ldots$

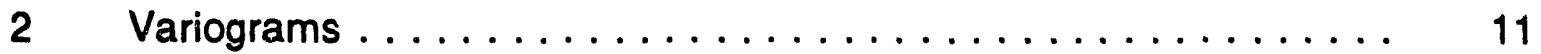

3 Correspondence of Standard Deviation to Coefficient of Variation .. 17 


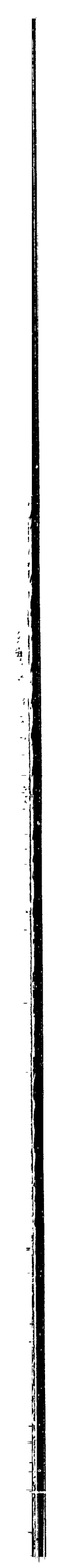




\section{EVALUATION OF ENVIRONMENTAL MONITORING THERMOLUMINESCENT DOSIMETER LOCATIONS}

\subsection{INTRODUCTION}

Thermoluminescent dosimeters (TLDs) have been placed at monitoring locations around the Nevada Test Site (NTS) for a number of years for the purpose of monitoring potantial worker exposure to external gamma radiation. The locations for monitoring were chosen to be in areas where work was in progress or where there was reason to expect elevated environmental gamma radiation levels, such as adjacent to waste management sites. Traditionally the locations of these munitoring stations were visually estimated by health physicists from maps. The gamma exposures derived from these TLDs have secondarily been used to estimate potential radiation doses for annual reports which are required by the U.S. Department of Energy. Recently the TLD locations have been accurately measured by Reynolds Electrical \& Engineering Co., Inc. (REECo) surveyors using a satellite Global Positioning System (GPS). This system was used to locate NTS TLDs with an error factor of less than $\mathbf{3 0}$ meters (100 feet).

This better location information offers the opportunity to perform a statistical assessment of the gross gamma estimation errors at any unmonitored location using spatial statistics methodologies. Prior to this GPS survey, coordinates were not recorded for all monitoring locations and the accuracy of the recorded monitoring locations was unknown. Thus, any conclusions reached using the earlier data could easily be challenged. The methodology chosen for this analysis is called kriging. Kriging has been used extensively at the NTS to estimate radiological inventories by the Nevada Applied Ecology Group (NAEG) and the Radiological Inventory and Distributioni Program (RIDP). Kriging is a linear estimation method that results in contour plots of both the pattern of the estimated gamma radiation over the area of measurements and also in contour plots of the standard deviations of the estimated levels. The plot of standard deviations can be used to define confidence limits on exposure estimates, and these limits, in turn, can be used as criteria to determine statistically whether additional monitoring locations are needed and where they should be located. This determination is accomplished by setting a maximum permissible error or confidence 
level for estimation; then, using the plots of standard deviations, any areas that exceed the criteria are candidates for additional monitoring stations. The standard deviations from kriging depend in part on the design of the sampling network that produced the data. Regions with low sampling density will tend to have higher standard deviations of estimated levels, and hence additional sampling locations will be indicated in these regions. The standard deviations also depend upon the variability within the data and the relationship of that variability to the spatial relationships of the sampling locations; this is measured by the variogram, which is discussed later.

\subsection{THE DATA}

\section{Monitoring Locations}

The Appendix coritains a listing of the current TLD locations and the 1990 exposures at each location. Figure 1 , is a graphic showing the NTS operational areas and the locations of the TLD monitoring stations. The abscissa and ordinate are central Nevada plane coordinates in feet, the traditional units used to establish NTS locations. The clusters of points in Areas 3,5 and 23 actually contain more sampling locations than appear at this scale. The dotted lines in Figure 1 delineate parts of the NTS that are significant to the data analysis triat follows. The area in the upper left of the northwest corner contains Pahute and Rainier Mesas, the area detailed in Figure 2. The upper and central right, or eastern and northeastern section of the NTS contains Yucca Flat, the area detailed in Figure 3.

An examination of Figure 1 shows that there are no monitoring stations in areas 14 , $16,26,29,30$ and most of Area 18. These are locations where no work is currently conducted and where access is restricted. The east part of Area 29 and the northeast part of Area 25 contain Shoshone Mountain, a rugged terrain feature that has few roads and has never been used for weapons testing. Areas 18 and 30 contain Buckboard Mesa, a formerly-used location that is now inactive. Areas 12, 19 and 20 contain Pahute Mesa, which is occasionally used for underground testing and where a number of post-test activities are in progress; Rainier Mesa, also in this sector, is used for testing in tunnels. The bulk of the remaining locations are in the northeast part of the NTS, Areas 6 and 11, and all Areas to the north of these. This region contains 


\section{TLD LOCATIONS}

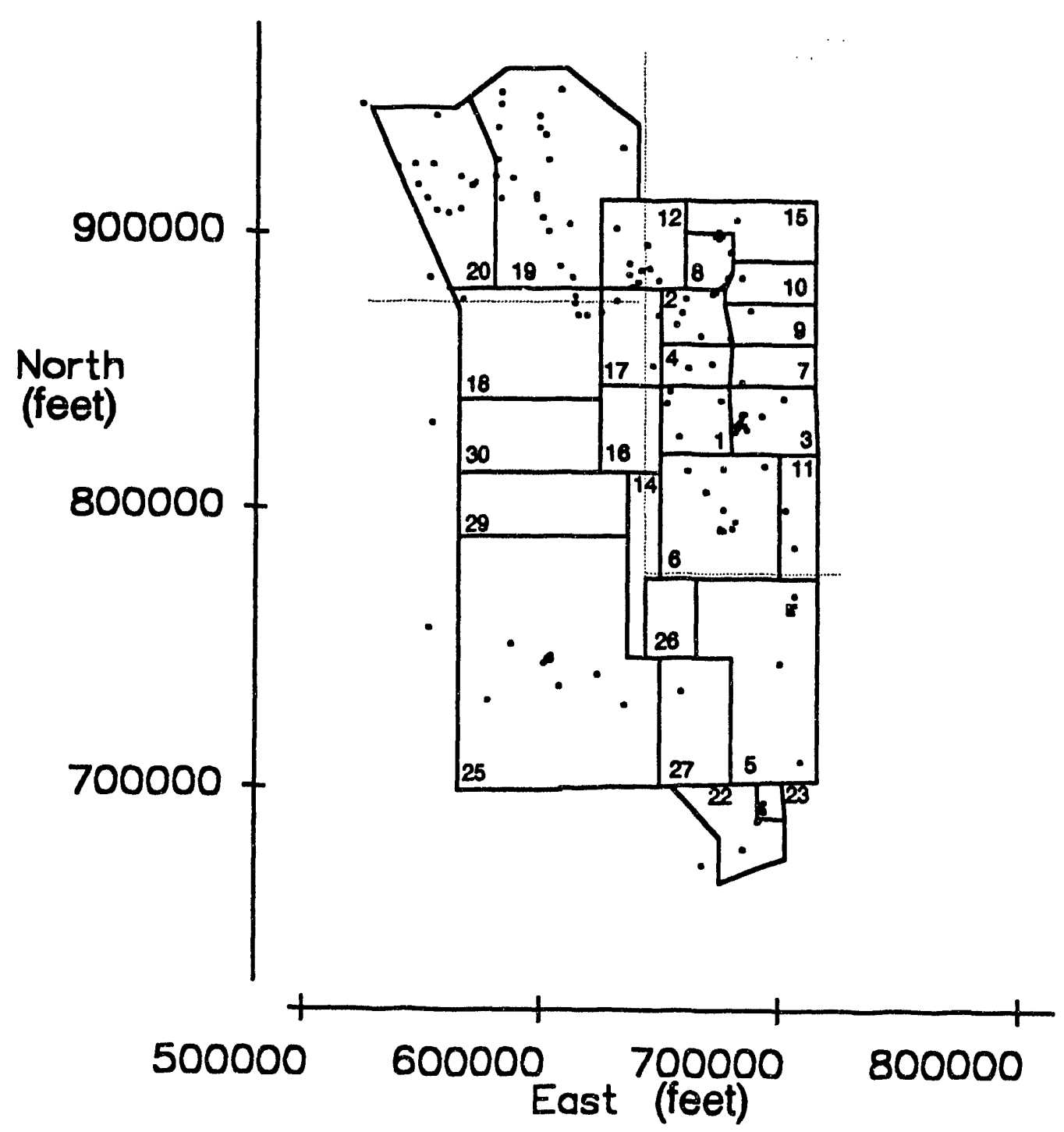

Figure 1. TLD Locations. 


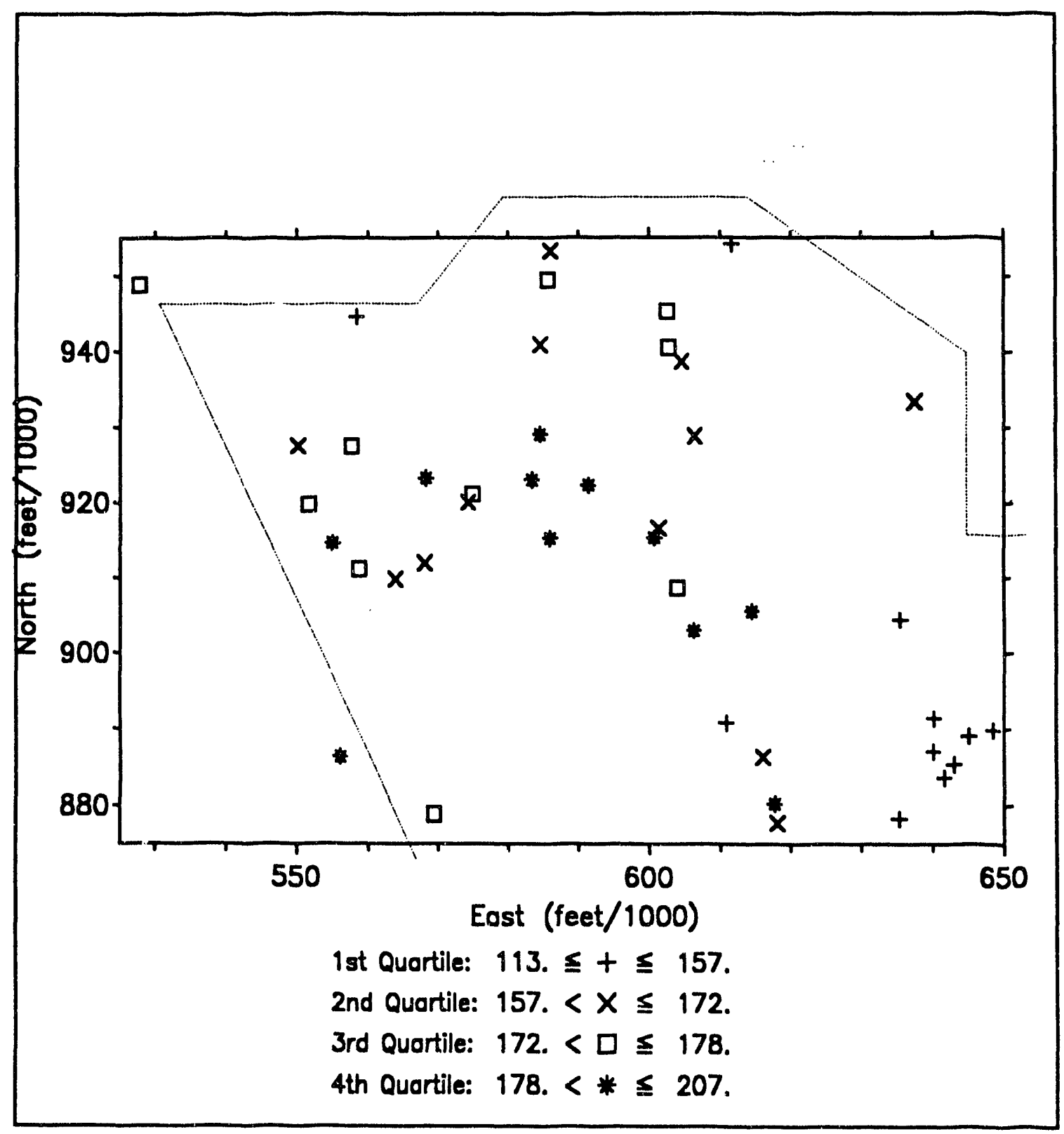

Figure 2. 1990 Pahute Mesa TLD Locations, mR/yr. 


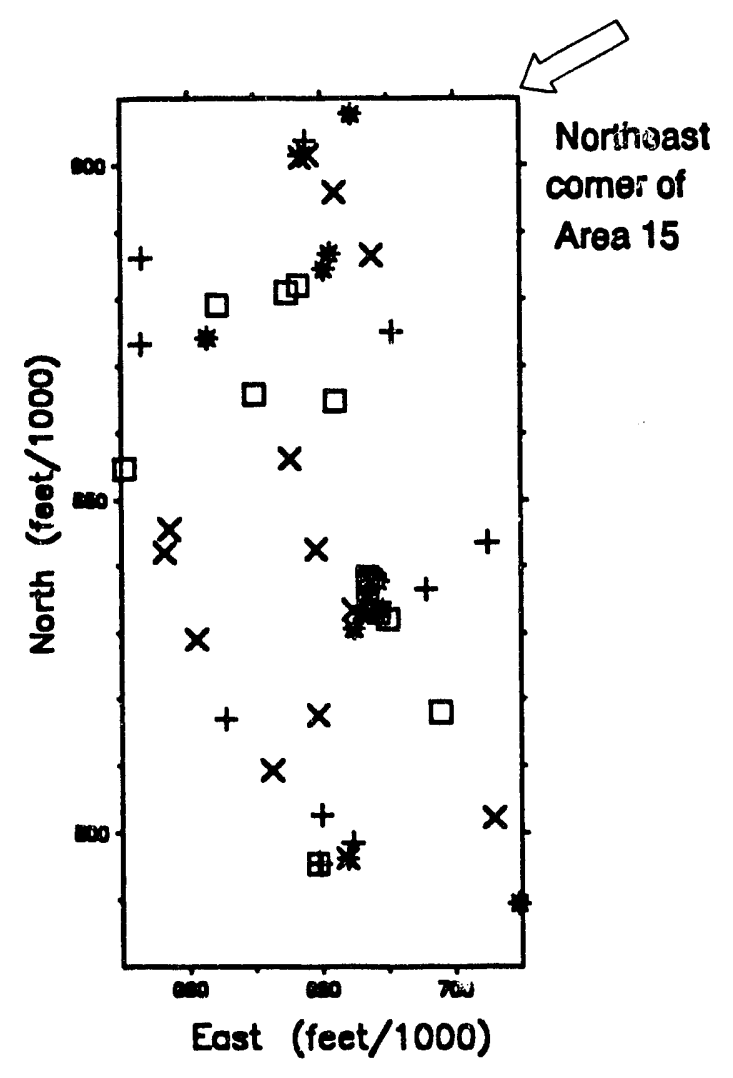

1at Quartile: 88. $\leqq+\leqq 119$.

2nd Quartile: 119. $<X \leqq 143$.

3rd Quartile: 143. $<\square \leq 167$.

4th Quartile: 167. <* $\leq 236$.

Figure 3. 1990 Yucca Flat TLD Locations, $m R / y r$. 
Yucca Flat, the main underground testing area of the NTS. The remaining part of the NTS is the southern third which is not currently used for testing, but contains support facilities. This area has few monitoring locations.

\section{Data Sampling and Screening}

The statistical assessment of environmental monitoring will be limited to those areas of the NTS where there is potential for new sources of exposure: Pahute and Rainier Mesas and Yucca Flat. (In other parts of the NTS there is negligible current potential for new exposure, and there is scant data for statistical analysis.) Since these two areas have very different physiographic characteristics they will be considered separately. Pahute and Rainier Mesis are a high plateau area with Great Basin types of plants and a hard rocky soil. $Y \ldots a$ Flat is a lower valley with alluvial soil and transitional type vegetation. To faciitate the separation of the data for these two analytical groups, the mesas will be defined as sampling locations north of Nevada Grid Coordinates $875000 \mathrm{~N}$ ano' west of $650000 \mathrm{E}$. Yucca Flat will be defined as east of $650000 \mathrm{E}$ and north of $780000 \mathrm{~N}$. These grid coordinates were used to define the dotted lines in Figure 1. This division defines two approximately rectangular areas containing adequate data for the statistical analysis.

The initial step in this statistical study is to use the techniques of exploratory data analysis to determine whether the underlying assumptions of kriging are met. Kriging provides a minimum variance unbiased linear estimator of a spatial variable at any specified location. This is called local estimation. In this study the spatial variable is the gross gamma exposure determined from the TLDs. Ordinary kriging as sumes that there is no "drift" in the data, which means that the data values are a realization of a two-dimensional random process. Exploratory data analysis techniques showed that the assumptions were satisfied by the data. Since the evaluation of the adequacy of the TLD network will use linear combinations of the standard errors of local estimates, it will also be necessary that the data have a normal (bell-shaped) probability density function.

The first step in the data screening was to examine normal probability plots of all the data, which are listed in the last column of the Appendix. If the data have a normal 
density they will approximately plot on a straight line in such a probability plot. The data did not meet this criterion, but the shap of the plot suggested that the data might have a lognormal density. (A lognormal density is such that the logarithms of the data have a normal density.) Figure 4 is a normal probability plot of the natural logarithms of the data. This plot shows two segments that join at a normal score value of about 1. This pattern is diagnostir, of a mixture of data from two normal populations. Since the lower segment is approximately a straight line, that portion of the data can be assumed to have a lognormal density. It is convenient to separate the data populations at the slight break in the data at a log-mR value of 5.5 , or an $\mathrm{mR} / \mathrm{yr}$ value of about 250. Table 1 lists the data that fall into the upper population in Figure 4.

Table 1 shows that most of the high-value data are from the TLDs that monitor the Radiological Waste Management Site (RWMS). All except one of the remaining locations in Table 1 are within areas of known contamination from early atmospheric tests. Stake J-31 is in the extreme northwest of the NTS and is approximately one mile north of Palanquin, a cratering test which had its plume carried north. The TLD locations in Table 1 cannot be considered environmental monitors for the purpose of evaluating the TLD network.

The purpose of this network design analysis is to evaluate its adequacy for environmental analysis. Since the sampling locations listed in Table 1 do not represent typical environmental conditions, they should not be used to evaluate the environmental monitoring network. Because the data in the lower segment of Figure 4 have a lognormal density, the logarithms of the data have a normal density and thus satisfy the underlying assumptions necessary for kriging. Thus only these data will be used in the remaining analyses.

Table 1. 1990 Data Above $250 \mathrm{mR} / \mathrm{yr}$

$\underline{\text { ID }}$

Location Name

235

278

288
Building 610 Bay

U3ax/bl Northeast

U3by North
East

697215

688497

687490
North

$\underline{m R / y r}$

674

310 
Table 1. 1990 Data Above $250 \mathrm{mR} / \mathrm{yr}$ (Continued)

\begin{tabular}{llrrr} 
ID & \multicolumn{1}{c}{ Location Name } & East & North & mR/yr \\
289 & U3co North & 686689 & 834258 & 1147 \\
290 & U3co South & 686879 & 833701 & 710 \\
294 & Stake A-9 & 664507 & 854035 & 08 \\
297 & Stake N-8 & 660199 & 869659 & 1445 \\
302 & Sedan West & 679299 & 883293 & 482 \\
314 & 7-300 Bunker & 687589 & 849218 & 375 \\
323 & T-Tunnel \#2 Pond & 647100 & 897963 & 394 \\
377 & Stake J-31 & 542993 & 927073 & 380 \\
605 & RWMS TRU Pad Norh & 708748 & 766248 & 829 \\
610 & RWMS MSM-1 Southieast & 710165 & 771839 & 487 \\
611 & RWMS MSM-1 East & 710144 & 771894 & 1007 \\
612 & RWMS MSM-1 Nor'heast & 710111 & 771930 & 566 \\
613 & RWMS MSM-1 North-Northeast & 710016 & 771893 & 2659 \\
614 & RWMS MSM-1 North-Northwest & 709934 & 771861 & 874 \\
615 & RWMS MSM-1 Northwest & 709845 & 771827 & 885 \\
616 & RWMS MSM-1 West & 709866 & 771774 & 2240 \\
617 & RWMS MSM-1 Southwest & 709883 & 771729 & 935 \\
618 & RWMS MSM-1 South-Southwest & 709976 & 771765 & 938 \\
619 & RWMS MSM-1 South-Southeast & 710068 & 771801 & 1434 \\
620 & RWMS MSM-2 Northeast & 709852 & 771577 & 1414 \\
621 & RWMS MSM-2 North & 709792 & 771544 & 2279 \\
622 & RWMS MSM-2 Northwest & 709734 & 771513 & 1388 \\
623 & RWMS MSM-2 West & 709767 & 771454 & 2939 \\
624 & RWMS MSM-2 Southwest & 709801 & 771391 & 1140 \\
625 & RWMS MSM-2 South & 709861 & 771424 & 3791 \\
627 & RWMS MSM-2 Southeast & 709919 & 771455 & 1789 \\
627 & RWMS MSM-2 East & 709886 & 771515 & 5581
\end{tabular}




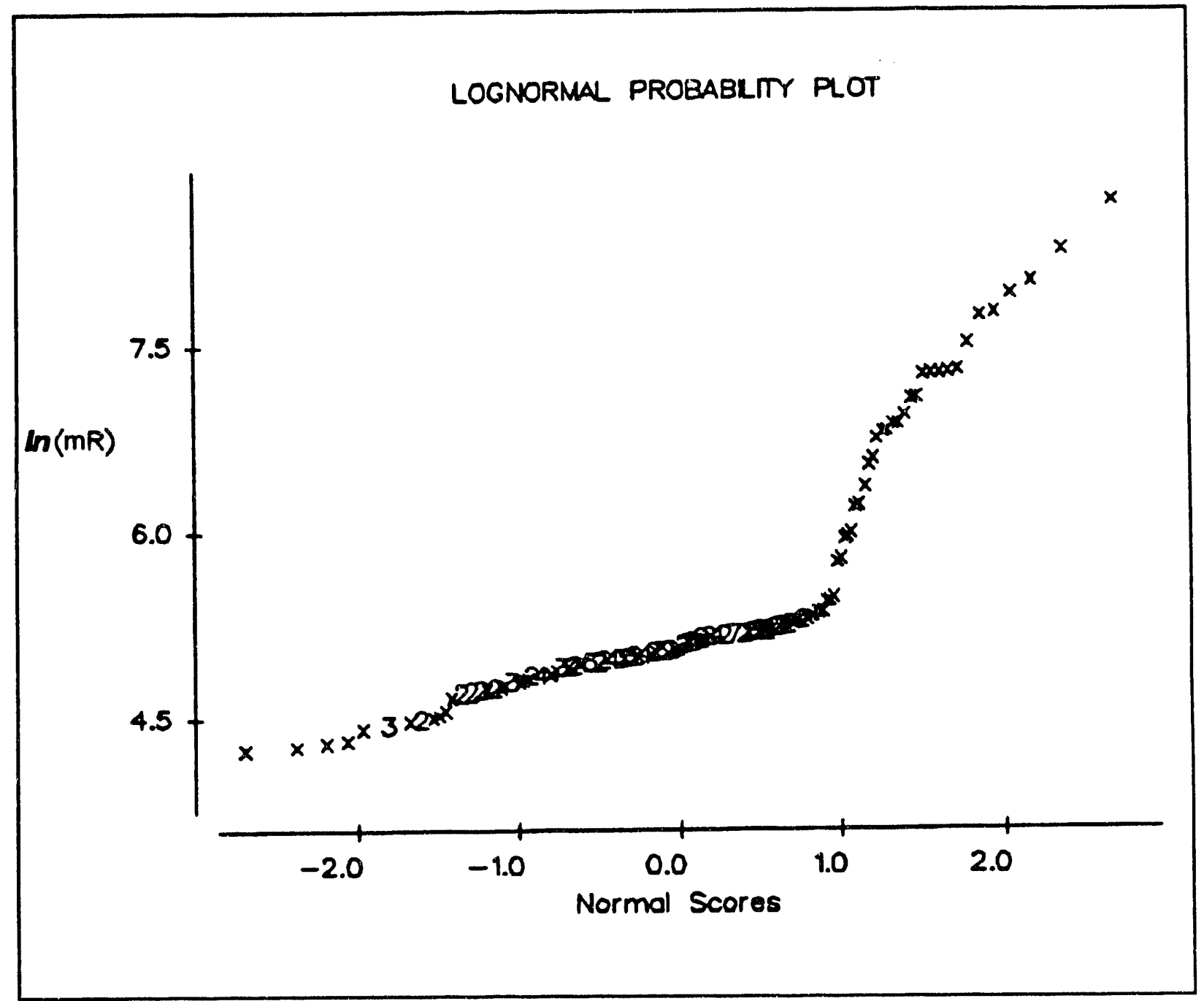

Figure 4. 1990 TLD Data. 


\subsection{DATA ANALYSES}

\section{Methodology}

Kriging is a sophisticated spatial statistics method developed to estimate ore reserves for the mining industry. It has been used extensively to analyze the spatial extent and concentrations of pollutants. The theory of kriging is much too lengthy to review in this document. Most current mathematical geology and statistical geology texts have several chapters describing kriging. A comprehensive presentation of kriging may be found in Journal and Huijbregts (1978). The implementation of kriging used for this paper was the personal computer program GEO-EAS available from the U.S. Environmental Protection Agency, Environmental Monitoring Systems Laboratory, Las Vegas, Nevada (Englund and Sparks, 1990). The following discussion of the kriging analysis of the NTS TLD data necessarily uses a number of terms unique to geostatistics, and which are not defined in this presentation because the definitions are lengthy and require a mathematical background to understand. There are three major steps in the kriging process: variogram analysis, kriging, and contouring.

\section{Variogram Analysis}

Kriging requires as input a description of how the variability between data values is related to the distance and direction between them. This relationship is provided by a curve or mathematical function called the variogram, or more correctly the semivariogram. This function is estimated by analyzing the data using the GEO-EAS modules PREVAR and VARIO. Variogram analysis has several steps itself, and there is no absolutely correct variogram; rather, a good variogram is chosen based on the data and the judgment of the investigator.

One of the steps in variogram analysis is to determine whether the data show anisotropy, a dependence of the variogram on the compass direction between sample stations. Four divisions of compass direction were used for this analysis: N-S, NE-SW, E-W, and SE-NW. The variogram of the subsets of the data related by these directions showed hardly any structure for either the mesas or Yucca Flat. The variogram plots for each area showed only random fluctuations around a sill, and the sills 
for the several directions were approximately the same. The sill is the value of the variogram when the distances between sampling locations are large enough to invalidate spatial relationships between locations; this is illustrated in Figure 5. Thus it was concluded that the data were isotropic or omnidirectional for both Yucca Flat and the mesas.

The next variogram step is to approximate the mathematical functions estimating the variogram. (In kriging there arc several standard functions, of which one is always used.) GEO-EAS allows a choice of only these functions. Table 2 gives the variogram models that were chosen for the analyses in this report. For convenience the Nevada Grid Coordinates describing the locations of sampling stations were divided by 1000 before the variogram and kriging analyses. Thus a range of 45 is geographically 45,000 feet and a location of $645 \mathrm{E}$ is $645,000 \mathrm{E}$.

Table 2. Variograms

$\begin{array}{lcc} & \text { Mesas } & \text { Yucca Flat } \\ \text { Shape } & \text { gaussian } & \text { spherical } \\ \text { Nugget } & 0.002 & 0.01 \\ \text { Sill } & 0.018 & 0.06 \\ \text { Range } & 45 & 15\end{array}$

\section{Kriging and Cross-Validation}

The actual kriging was accomplished using the GEO-EAS module KRIGE. Input to this module is the variogram model and the data. The module was set up to do ordinary block kriging on square blocks 5000 feet on a side. The module output is an estimated average and standard deviation for each block, which may be contoured for visualization of patterns. Figures 2 and 3 show the locations of the TLD's for the mesas and Yucca Flat respectively and divide the exposure level data into quartiles. Quartiles, by definition, divide the data into four parts, each containing one-fourth of the data. For the convenience of the reader, gamma radiation levels rather than the corresponding logarithms were used for these figures. There are substantial portions 


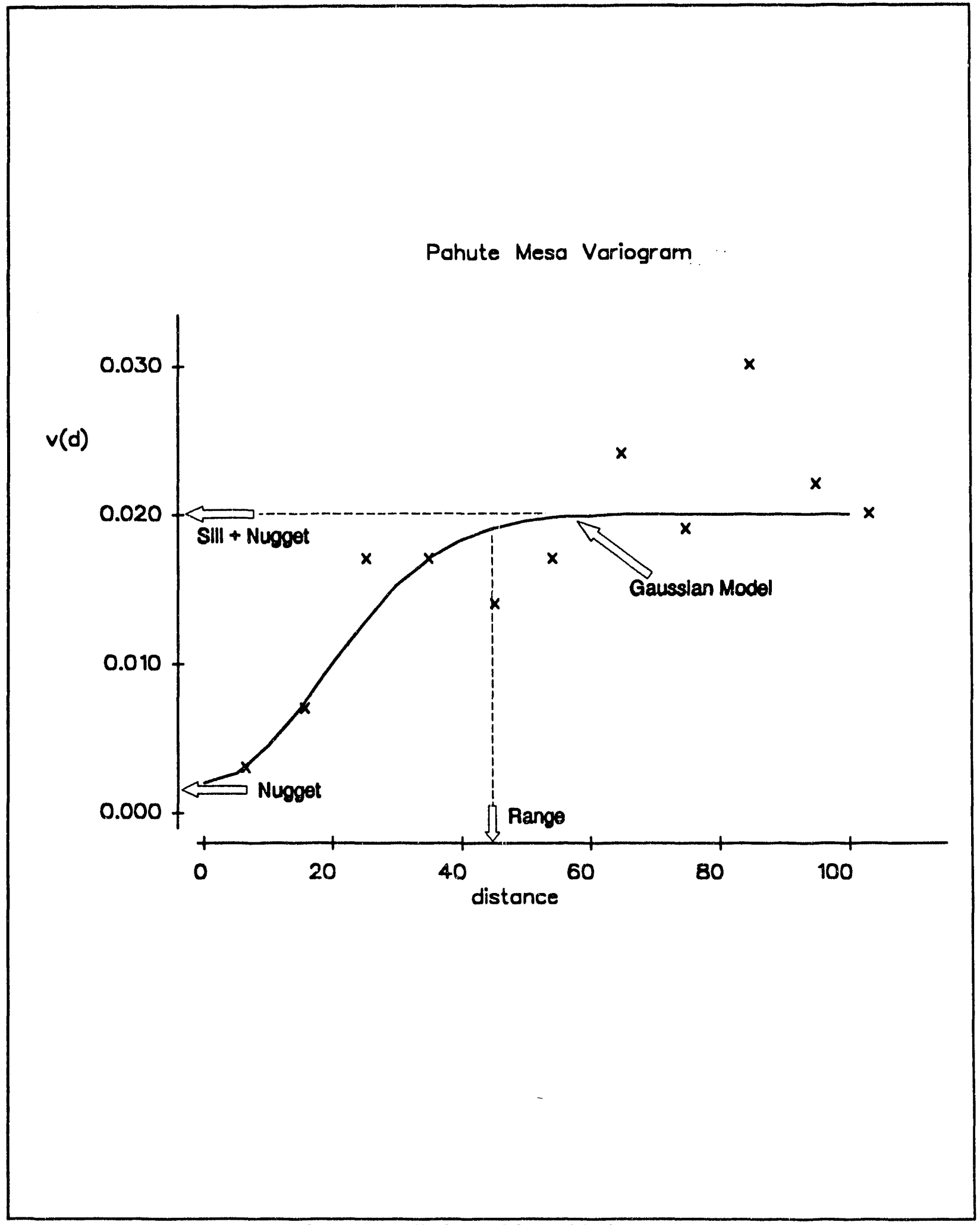

Figure 5. Pahute Mesa Variogram. 
of the mesas with no TLD stations, particularly in the south-central and northeastern parts of Figure 2. The dotted line in Figure 2 approximates the northwestern boundaries of the NTS. Figure 2 should be compared to Figure 1 for perspective.

Figure 3 details the locations and quartiles of the Yucca Flat data. This figure should be compared to Figure 1 for perspective. The " $x$ " in the center of Figure 3, slightly above 680 East and 840 North, is the sampling siation at the BJY road junction, a major landmark location for the NTS. BJY is close to the place where Areas 4, 7, 1 and 3 join (see Figure 1). An important characteristic of Figure 3 is that there are several clusters of sampling locations, particularly the large cluster just southeast of BJY which shows the many TLDs around the Bulk Waste Management Facility. These clusters are important to the data cross-validation which is discussed next. The square with a plus inside at the bottom center of the figure represents the two sampling locations at the Control Point (CP), the location where test directors control nuclear tests. The arc of $x$ 's and t's in a northwesterly direction from the CP are stations along the Tippipah Highway. There are no sampling stations southwest of this highway because of inaccessible mountainous terrain.

Cross-validation is a procedure that determines whether the kriging estimates adequately approximate the observed data values. This is performed by deleting the data values one-by-one from the data set and then kriging an estimate of the deleted value using the re naining data values. The deviation between each data value and its estimate, or ine residual, can then be examined for spatial pattern. The results of this analysis indicated that the assumed variogram models are acceptable.

The plot of cross-validation residuals for Yucca Flat showed small residuals where the sampling stations are spread out. At the locations where stations are clustered, these residuals tend to show both large positive and large negative values. (The term "large" as used here is relative; these "large" residuals were very small when compared to the range of the data values. They are only large when compared to the residuals found at the more isolated sampling locations.) This spread in values indicates that kriging produced estimates in the middle of the data values, even though there are some differences among data values that are spatially close together. The 
mean residual, in natural logarithms, for Yucca Flat was 0.013 and the standard deviation was 0.226 .

The cross-validation results for Pahute and Rainier Mesas were similar to the Yucca Flat results, although the clustering effect was much less distinct because the clustering consists of only a few pairs of points. Thus the conclusion that kriging adequately models the TLD spatial variability at the NTS is reasonable. The mean residual, in natural logarithms, for Pahute and Rainier Mesas was -0.001 with a standard deviation of 0.12 .

\section{Contouring}

The kriging module of GEO-EAS creates a regular grid of values from the irregularly located data points. For the NTS TLD data, the grid consists of kriged block $\ln (\mathrm{mR} / \mathrm{yr})$ averages, standard deviations, and the location coordinates of the center of each block. The CONREC module in GEO-EAS uses spline functions to calculate isopleth contours from the regular grid of values. The user can specity the contour levels and the contour labels. This feature was used to draw and label contours at specified $\mathrm{mR} / \mathrm{yr}$ levels even though the kriging used the natural logarithms of the data. This was done to make the interpretation of radiation levels more understandable for the reader.

Figure 6 shows the $\mathrm{mR} / \mathrm{yr}$ levels for Yucca Flat, and Figure 7 shows the corresponding kriging standard deviations in the log scale. Note that no contours are to be found in the southwest corner of Figure 6; there is insufficient data for that area to calculate kriging estimates. This lack of data was described in the discussion of Figure 3. The general shape of the contours in Figure 6 agrees in shape with the contours of other radiological surveys of Yucca Flat. Thus it may be concluded that the TLD network, as it now exists, produces enough information to reasonably define the general pattern of environmental exposure levels in Yucca Flat, and that the pattern agrees with the results of surveys that were done in the past to define radiological exclusion areas. The contours of the kriging standard deviations are in the log scale since lognormal kriging was used with this data, so a conversion is necessary before these contours can be compared to the actual data from the $\mathrm{mR} / \mathrm{yr}$ contours. A convenient and 


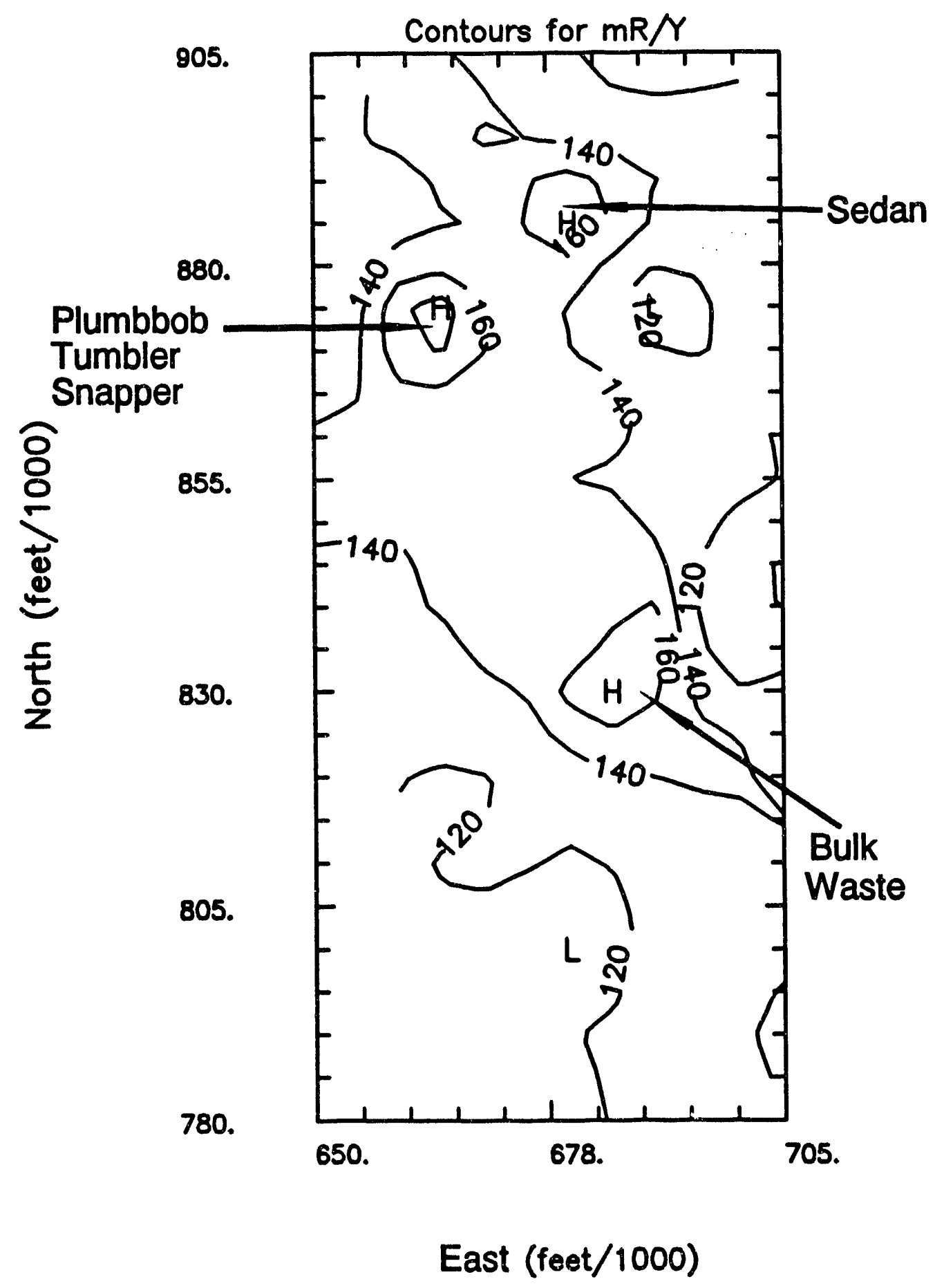

Figure 6. Kriging Estimates for Yucca Flat. 


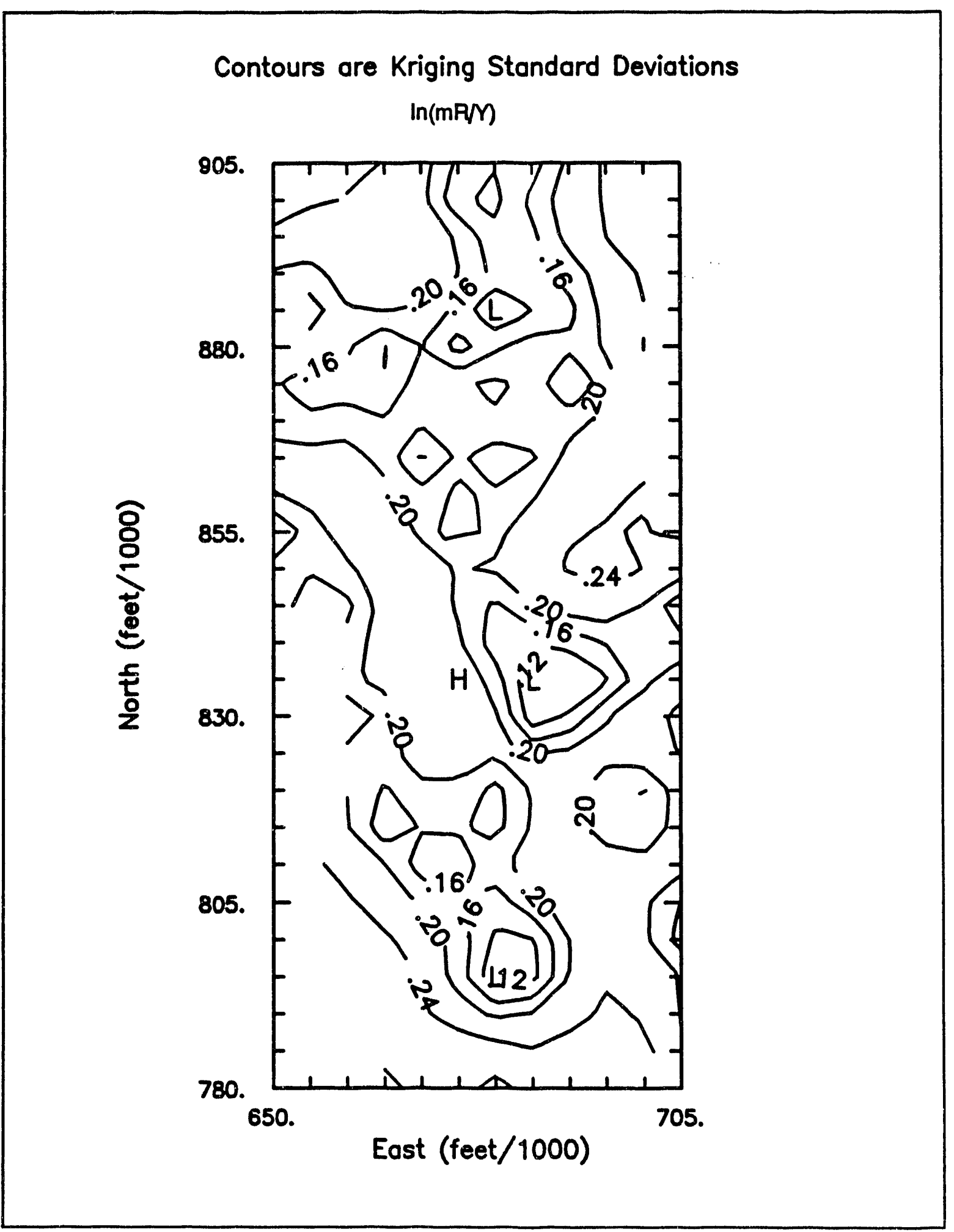

Figure 7. Kriging Standard Deviations for Yucca Flat. 
commonly used transformation of the standard deviation is the coefficient of variation or relative standard deviation. This coefficient expresses the standard deviation as a fraction or multiple of the corresponding mean value. One of the characteristics of lognormally distributed data is that the standard deviation is not constant, rather, it is proportional to the mean. As a result of this, the coefficient of variation is constant and is typically used by statisticians to record lognormal variability. Equation 1 is used to convert the logarithmic standard deviation, denoted by $\sigma$, to the arithmetic coefficient of variation (cv).

$$
c v=\left(\exp \left(\sigma^{2}\right)-1\right)^{1 / 2}
$$

Applying this equation to some typical values from Figures 7 and 9 gives the following table of correspondences:

Table 3. Correspondence of Standard Deviation to Coefficient of Variation.

$\begin{array}{cc}\underline{\sigma} & \underline{\mathrm{CV}} \\ 0.04 & 0.040016 \\ 0.06 & 0.060054 \\ 0.10 & 0.10025 \\ 0.16 & 0.16103 \\ 0.20 & 0.20202 \\ 0.24 & 0.24350\end{array}$

Thus, for the range of values of the kriging standard deviations of the natural logarithms of the data found in Figures 7 and 9, these standard deviations are a reasonable approximation of the coefficient of variation of the kriging estimates. In the following discussion the coefficient of variation and standard deviation will be used interchangeably. It should be remembered that the coefficient of variation is a unitless ratio which specifies the magnitude of the standard deviation relative to the corresponding mean, and the standard deviation has the same units of measurement as the mean. For the special case of this data set, it coincidentally happens that the magnitude of the standard deviations of the logarithms of the data is almost the same 
as the magnitude of the coefficient of variation of the data (without the logarithmic transformation).

Figure 7 gives the kriging standard deviations (in the natural logarithm scale) corresponding to Figure 6 . This figure shows that the coefficients of variation are typically around 20 percent with a few areas of lower values, and a few areas of 24 percent or higher. The lower value areas are places where there are many TLDs: the Bulk Waste Management site and CP, as indicated in Figure 3. The high-value areas tend to be around the periphery where there are few TLD stations. The extreme southwest corner of Figure 7 is the southwest half of Area 6, which was explained in the discussion of Figure 3. The high-value area at the northwest corner of Figure 7 is the eastern quarter of Area 12 and the western part of Areas 8 and 15. These parts of the NTS are also difficult to access. The high-value area along the upper right of Figure 7 contains the extreme eastern quarters of Areas 7, 9, 10 and 15, which is a mountainous sector with poor access. The area in the central west portion of Figure 7, with a standard deviation of 0.2 or greater is in the western half of Yucca Flat. This area is accessible, but currently is not being used for testing. This pattern of standard deviation contours indicates that the kriging estimation errors are strongly influenced by the monitoring station locations, and for much of Yucca Flat, th, e coefficient of variation is 20 percent or higher.

Figures 8 and 9 present the contours for Pahute and Rainier Mesas corresponding to the Yucca Flat data in Figures 6 and 7 . The contours of these figures do not completely fill the southwest and northeast corners which are located outside the NTS; this exclusion was discussed in the description of Figure 2. The northwestern boundaries of the NTS are indicated by the dotted lines. Figure 8 shows a central high region: note that there is no $200 \mathrm{mR} / \mathrm{yr}$ contour within this region, thus the highest estimated radiation levels are less than 200 . This high-value region is in the north-central part of Area 19, a region where there has been a number of underground tests, some of which are seeping radioactive noble gasses. The increasing values indicated toward the southwest are due to the single high-value $(207 \mathrm{mR} / \mathrm{yr})$ at boundary station 350 . The asterisk in the lower left of Figure 2 indicates the location of this station. Additional monitoring stations in this localized region could substantially change the estimated contour pattern and could be recommended. Contour levels decline toward the 


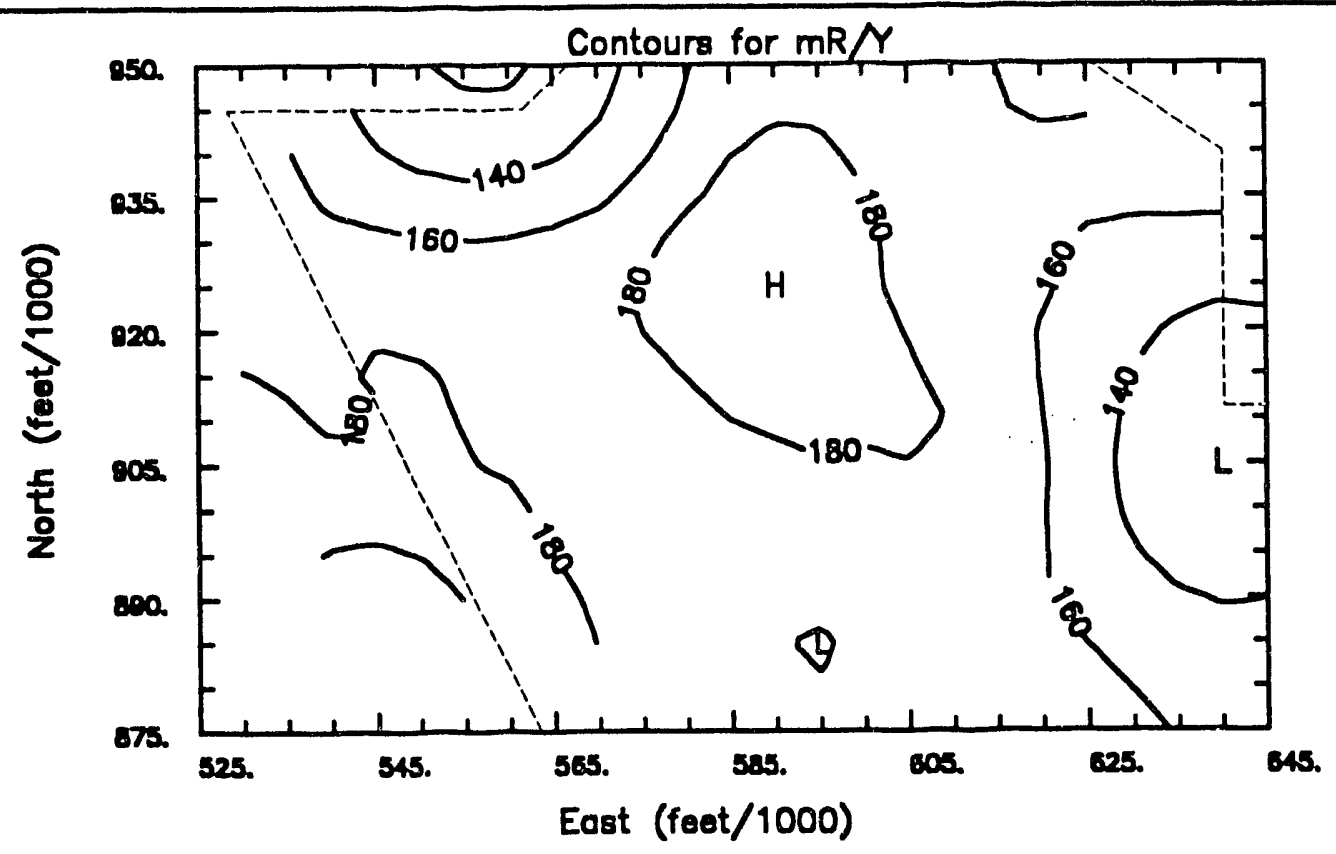

Figure 8. Kriging Estimates for Pahute Mesa.

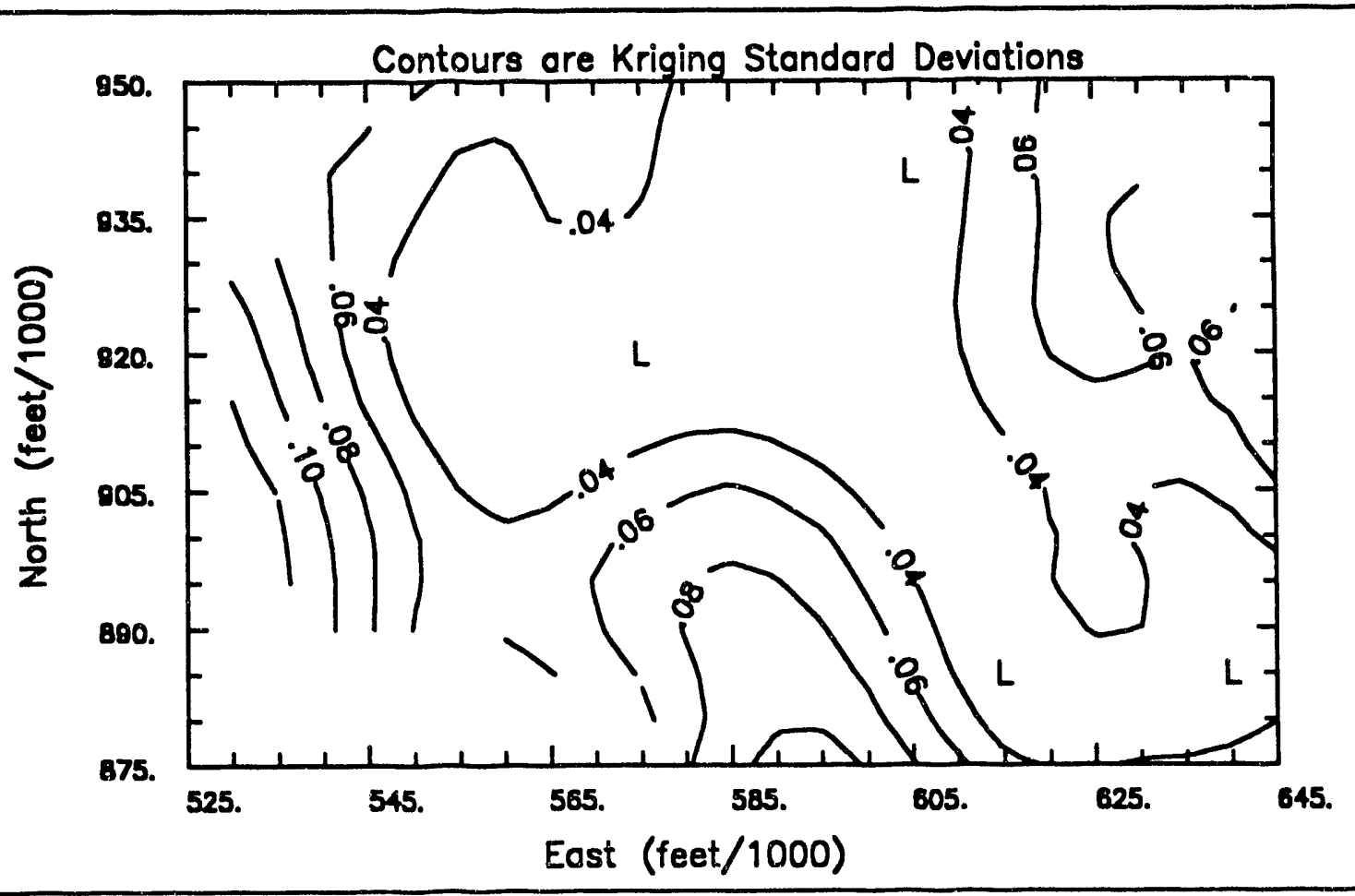

Figure 9. Kriging Standard Deviations for Pahute Mesa. 
northwest and east where the boundaries of Figure 8 approximate the northern and eastern boundaries of the NTS.

The contours of the lognormal kriging standard deviations for the mesas (Figure 9) show a general pattern of central low values with values increasing towards the boundaries of the figure. Note that there is no 0.02 contour in the center of the figure so it may be concluded that all values are above 0.02 . Contour values increase more rapidly in the lower central section of Figure 9, because there are no sampling stations between the Pahute Mesa Highway and the Buckboard Mesa Highway. Pahute Mesa Highway approximately follows the 0.04 contour in the lower central portion of Figure 9, and Buckboard Mesa Highway is below the lower edge of the figure. Rugged terrain without access roads also predominates in the area of the NTS between these highways.

A comparison of Figures 6 and 7, giving the results for Yucca Flat, with Figures 8 and 9, giving the results for the mesas, shows some notable patterns. The mi/yr levels for Yucca Flat are slightly lower than for the mesas. The mesas show essentially a single large central area of high values with decreasing values as one moves away from this central area. Yucca Flat shows a more intricate pattern with several small high-value regions and a couple of Inr:alized low regions. Values also decrease toward the periphery of Figure 8. The comparison of Figures 7 and 9, the standard deviations for Yucca Flat and the mesas, also shows a much more intricate pattern for Yucca Flat. However, in contrast to the gamma levels, the standard deviations are lower on the mesas than on Yucca Flat. The kriging standard deviations are sirongly influenced by the spacing of sampling locations and the variogram. The localized low regions in Figure 7 correspond to the clusters of sampling locations identified in Figure 3. What clustering of locations occurs on the mesas, as shown in Figure 2. consists of no more than two locations close together, and this is insufficient to significantly influence the pattern in Figure 9.

\subsection{DISCUSSION}

Figures 6 and 8 , and the cross-validation results indicate that kriging has satisfactorily modeled the spatial variability of annual gross gamma exposures for Yucca Flat, and 
for Pahute and Rainier Mesas when the high-data values from the radiological waste manazement facilities are deleted. The cross-validation showed that the estimation errors are small compared to the range of values of the data. Figures 6 and 8 showed that the patterns of regions of high and low values agree with the results of other radiological surveys of the NTS (unpublished radiological safety maps). Thus it is reasonable to use the kriging standard deviations to determine where additional sampling locations would most reduce the estimation errors, or where sampling locations could be removed without substantially increasing estimation errors. At the NTS it is operationally unreasonable to eliminate the clusters of sampling locations because those clusters were established to monitor very localized phenomena, such as which direction from a waste management site an exposure plume would travel.

The major factors influencing the kriging estimation errors that are controlled by the network designer at the NTS are the location and spacing of sampling stations. There are a few NTS areas where desired sampling locations are difficult to access because of rugged terrain and lack of roads. A comparison of Figures 3 and 7 shows that the standard deviations for Yucca Flat are close to $0.2 \mathrm{mR} / \mathrm{yr}$ where the sampling locations are about 10,000 feet (about two miles) apart. Wider spacing is associated with larger standard deviations, and closer spacing, with smaller standard deviations. The comparison of Figures 2 and 9 shows that the standard deviations for the mesas are about 0.04 where the sampling locations are close to 10,000 feet apart. The difference between the standard deviations of Yucca Flat and the mesas for similarly-spaced locations is due to the differe sions of the different physical geographies of the two regions.

The fact that a single variogram does not seem to be applicable to all parts of the NTS is a very important consideration for any future environmental sampling design. The shape of the variogram is determined by spatial correlations, and the differing shapes noted in this report may be due to the several physical geographies found within the NTS. For the southern and western areas of the NTS (which were not considered in this report because of inadequate data) it may be desirable to use a two-staga network clesign, i.e., first, an exploratory network to estimate the variogram and kriging standard deviations; second, the variogram and kriging standard deviations thus estimated can be used to design a network that meets requirements. 
Before using environmental sampling design to modify the existing networks or to establish designs for regions not now monitored, it is necessary to have a management decision specifying the required degree of accuracy. A raasonable measure of accuracy for radiological monitoring and kriging is a specification of an upper limit for the kriging estimation coefficient of variation. As a starting point, a coefficient of variation of 10 percent for active areas and 20 to 25 percent for inactive areas is suggested. A final choice of such criteria should include consideration of a cost-benefit analysis. Using these suggested criteria, the current sampling locations on the mesas are adequate, except possibly for a portion of the region between the Pahute Mesa and Buckboard Mesa highways. However, almost none of Yucca Flat meets these criteria, indicating that an extensive redesign of the sampling network in that region may be necessary.

Geostatisticians have shown that a regularly-spaced grid of sampling locations is theoretically the most efficient design for minimizing kriging standard deviations and that as the spacing between locations decreases, so do the standard deviations (Parkhurst, 1984; Olea, 1984). These design criteria should be used for any new design or for an extensive redesign of an existing network. The existing network for Yucca Flat showed a 20 percent coefficient of variation for a spacing of 10,000 feet with an irregular pattern of sampling locations. This result suggests that a spacing of 5,000 feet and a regular grid of locations should readily achieve a maximum coefficient of variation of 10 percent. Another important statistical consideration is the specification of the size of the kriging blocks. Size determines the "area of concern" for a hypothetical worker; confidence in exposure estimates is a function of the size of this area. The 5000 feet (about one mile) on-a-side kriging grid size was used in this study, because it seemed a reasonably-sized environmental unit; a more rigorous evaluation could change this specification.

An alternate design strategy typically is used in situations where only a limited portion of an existing network does not meet the design criteria. Such is the case for Pahute and Rainier Mesas. The strategy would be to add sampling stations only in those regions that exceed the design criteria. For the mesas this strategy calls for additional stations in the region between the Pahute Mesa and Buckboard Mesa highways. Since a coefficient of variation of 0.04 is associated with a sample spacing of 
10,000 feet on the mesas, linear interpolation would indicate that a sample spacing of 25,000 feet (about five miles) should be adequate to achieve a coefficient of variation of 10 percent. These highways delimit an approximately rectangular region somewhat less than 10 miles southwest to northeast and somewhat more than 10 miles northwest to southeast. Thus two additional sampling locations are suggested, one in the northwest quadrant of this region and one in the southeast quadrant. These stations should be about five miles apart and also five miles from existing monitoring locations. Thus, on Figure 2, a station should be located about 585,000 East and 895,000 North. The second station should be located just off the south boundary of this figure about 595,000 East and 790,000 North. Since these locations have no roads, are not used for any human activities, and are in rugged terrain, the expense of helicopter access becomes an important consideration in determining whether establishing these additional stations would be cost-effective. It may be that these additional stations could be implemented only when the potential for human exposure increases in this region and access roads are built.

A final statistical consideration should be mentioned. In this presentation the contours of exposure levels were used only in a restricted way for several reasons. First, the backtransform from logarithms to the original measurement units introduces some bias into the results. Since the bias varies with the estimated levels and standard deviations, it is difficult to account for in the analysis. Second, the kriging block averages are typically used to calculate an inventory for the region kriged, but an inventory is a meaningless concept for gross gamma exposure levels. Other NTS radiological surveys have reported results in units such as $\mu \mathrm{Ci} / \mathrm{gm}$ of soil or $\mathrm{nCi} / \mathrm{M}^{2}$ which are not directly convertible into $\mathrm{mR} / \mathrm{yr}$; thus only the pattern of high and low values can be compared.

\subsection{SUMMARY}

Geostatistics, particularly kriging, has been used to assess the adequacy of the existing thermoluminescent dosimeter network for determination of environmental exposure levels. Even though the network was not designed as an environmental monitoring network, it adequately serves this function in the region of Pahute and Rainier Mesas. The network is not adequate for environmental monitoring in Yucca 
Flat if a coefficient of variation of 10 percent or less is chosen as the criterion for network design. A revision of the Yucca Flat network design should be based on a square grid pattern with nodes 5000 feet (about one mile) apart, if a 10 percent coefficient of variation criterion is adopted. There was insufficient data for other sections of the NTS to perform the geostatistical analysis. A very significant finding was that a single network design cannot be used for the entire NTS because different areas have different variograms. Before any design can be finalized the NTS management must specify the exposure unit area and coefficient of variation that are to be used as design criteria. 


\section{REFERENCES}

Englund, E, and A. Sparks, 1990. "Geostatisticai Environmental Assessment Software, Users Guide, GEO-EAS 1.2.1. Environmenia! Monitoring Systems Laboratory, Office of Research and Development, U.'S. Environmental Protection Agency, Las Vegas, Nevada.

Journal, A. G., and Ch. J. Huijbregts, 1978. Mining Geostatistics, Academic Press.

Olea, R.A. 1984. Sampling Design Optimization for Spatial Functions. Mathematical Geology, 16:369-392.

Parkhurst, D.F. 1984. Optimal Sampling Geometry for Hazardous Waste Sites. Environ. Sci. Technol. 18:521-523. 


\section{APPENDIX \\ DATA LISTING}

This appendix contains a listing of the data used in this report. The first two columns contain the monitor station identification code and standard name. The next two columns contain the location in Central Nevada State Plane Coordinates, the traditional measurement method for establishing locations within the Nevada Test Site. Plane Coordinates are measured feet from an arbitrary origin. Since Kriging uses linear measures of location it was more convenient to use these traditional measures than to work with degrees, minutes and seconds of latitude and longitude. The final column contains the 1990 gross gamma mR/yr measures for each location.

$\underline{\text { ID }}$

$\begin{array}{ll}0230 & \text { Building 650 Storage Room } \\ 0231 & \text { Building 650 Dosimetry } \\ 0232 & \text { Building 650 Roof } \\ 0233 & \text { Post Office } \\ 0234 & \text { Building } 610 \text { Gate } \\ 0235 & \text { Building } 610 \text { Bay } \\ 0236 & \text { Gate 100 } \\ 0237 & \text { Desert Rock Control Tower } \\ 0238 & \text { Building 190 Bench Drawer } \\ 0239 & \text { Building 180 Scaler Room } \\ 0240 & \text { NRDS Warehouse } \\ 0241 & 25-4 P \text { Gate } \\ 0242 & 25-7 P \text { Gate } \\ 0243 & \text { E-MAD North } \\ 0244 & \text { E-MAD East } \\ 0245 & \text { E-MAD South } \\ 0246 & \text { E-MAD West } \\ 0247 & \text { Henre } \\ 0248 & \text { Area 27 Cafeteria } \\ 0249 & \text { Well 5B }\end{array}$

\section{East}

697193

697193

697193

696663

697107

697215

694944

688168

696748

697070

610646

581006

591211

605516

607032

606986

605892

626993

662018

704109
North

$\underline{m R / y r}$

$\begin{array}{rr}694633 & 87 \\ 694633 & 73 \\ 694633 & 69 \\ 694923 & 83 \\ 693995 & 75 \\ 693775 & 674 \\ 691032 & 71 \\ 680732 & 83 \\ 696903 & 156 \\ 697858 & 113 \\ 739173 & 142 \\ 734581 & 145 \\ 753923 & 159 \\ 747154 & 125 \\ 750226 & 135 \\ 747930 & 134 \\ 748822 & 128 \\ 743136 & 143 \\ 737354 & 146 \\ 747097 & 125\end{array}$




\begin{tabular}{lllll} 
ID & \multicolumn{1}{c}{ Location Name } & East & North & mR/yr \\
\hline & & & & \\
0250 & RWMS East 1500' & 709401 & 766499 & 139 \\
0251 & RWMS East 1000' & 709401 & 766997 & 144 \\
0252 & RWMS East 500' & 709403 & 767603 & 139 \\
0253 & RWMS Northeast Corner & 709401 & 767997 & 139 \\
0254 & RWMS North 1500' & 708907 & 767999 & 139 \\
0255 & RWMS North 1000' & 708400 & 768001 & 141 \\
0256 & RWMS North 500' & 707913 & 767999 & 152 \\
0257 & RWMS Northwest Corner & 707413 & 767998 & 145 \\
0258 & RWMS West 500' & 707410 & 767497 & 142 \\
0259 & RWMS West 1000' & 707413 & 766998 & 153 \\
0260 & RWMS West 1500' & 707400 & 766503 & 149 \\
0261 & RWMS Southwest Corner & 707413 & 765995 & 136 \\
0262 & RWMS South 500' & 707909 & 765997 & 142 \\
0263 & RWMS South Gate & 708385 & 765998 & 119 \\
0264 & RWMS East Gate & 708901 & 765989 & 136 \\
0265 & RWMS Office & 709153 & 766093 & 110 \\
0266 & CP-6 & 679787 & 795283 & 90 \\
0267 & CP-2 Logistic Desk & 679368 & 795534 & 88 \\
0268 & CP-50 Calibration Door & 679370 & 795332 & 162 \\
0269 & CP-50 Calibration Bench & 679370 & 795332 & 111 \\
0270 & Yucca Oil Storage Area & 684588 & 798472 & 116 \\
0271 & Decontamination Pad Office & 683815 & 796175 & 120 \\
0272 & Decontamination Pad Back Room & 683835 & 796155 & 111 \\
0273 & Gate 293 & 705882 & 802248 & 132 \\
0274 & Stake OB-11.5 & 697902 & 818016 & 145 \\
0275 & Stake OB-20 & 695768 & 836475 & 104 \\
0276 & U3AX/BL South & 688231 & 837837 & 173 \\
0277 & U3AX/BL Southeast & 688500 & 837677 & 196 \\
0278 & U3AX/BL Northeast & 688497 & 838220 & 319 \\
0279 & U3AX/BL Northwest & 687843 & 838436 & 208 \\
0280 & LANL Trailers & 684749 & 833432 & 141 \\
0281 & Stake A-6.5 & 684816 & 830562 & 186
\end{tabular}




\begin{tabular}{llrrr} 
ID & \multicolumn{1}{c}{ Location Name } & East & North & mR/yr \\
0282 & U3DU South & 686049 & 832898 & 203 \\
0283 & U3BY South & 687637 & 832928 & 181 \\
0284 & U3BZ South & 688526 & 832934 & 164 \\
0285 & U3EY South & 690015 & 832000 & 159 \\
0286 & U3CJ North & 689191 & 833443 & 196 \\
0287 & U3BZ North & 688236 & 833457 & 230 \\
0288 & U3BY North & 687490 & 833436 & 310 \\
0289 & U3CO North & 686689 & 834258 & 1147 \\
0290 & U3CO South & 686879 & 833701 & 710 \\
0291 & U3DU North & 684898 & 830551 & 186 \\
0292 & Well 3 & 679401 & 817544 & 123 \\
0293 & BJY & 679190 & 842543 & 139 \\
0294 & Stake A-9 & 664507 & 854035 & 1408 \\
0295 & Stake M-130 & 675185 & 856133 & 135 \\
0296 & Stake M-140 & 669965 & 865670 & 150 \\
0297 & Stake N-8 & 660199 & 869659 & 1445 \\
0298 & Stake L-9 & 662802 & 874065 & 236 \\
0299 & Stake M-150 & 664351 & 878928 & 152 \\
0300 & Cable Yard & 674840 & 880871 & 167 \\
0301 & Stake CA-14 & 676603 & 881940 & 153 \\
0302 & Sedan West & 679299 & 883293 & 482 \\
0303 & Sedan East Visitor Box & 680472 & 884372 & 174 \\
0304 & Stake A-24 & 681353 & 886666 & 210 \\
0305 & EPA Complex & 682225 & 895840 & 124 \\
0306 & Stake K-25 & 678231 & 901465 & 122 \\
0307 & Office & 677684 & 903525 & 109 \\
0309 & Lamp Shack & 676999 & 901038 & 143 \\
0310 & Substation U15E & 676864 & 901293 & 109 \\
0312 & Circle \& L Road & 687772 & 886490 & 142 \\
0313 & 9-300 Bunker & 682162 & 864586 & 148 \\
0314 & 7-300 Bunker & 687589 & 849218 & 375 \\
0315 & Stake TH-1 & 679931 & 802637 & 91
\end{tabular}


East

0316 Stake TH-9

0317 Stake TH-18

0318 Stake TH-28

0319 Stake TH-38

0320 Stake TH-48

0321 Stake TH-58

0322 Stake TH-68.5

0323 T-Tunnel \#2 Pond

$0324 \quad$ Building 12-10

0325 Upper N Pond

0326 Stake M-168

0327 Upper Haines Lake

0328 Stake M-170

0329 Stake M-175

0330 Stake M-185

0331 Stake M-190

0332 Stake M-196

0333 Stake P-35

0334 Stake P-39

0335 Stake P-41

0336 Stake P-46

0337 Stake P-54

0338 Stake P-59

0339 Stake P-66

$0340 \quad$ Stake P-71

0341 Upper Well U19C Reservoir

0342 Stake C-31

0343 Stake C-27

0344 Stake C-25

0345 Stake C-16

0346 Boundary TLD Station 346

$\begin{array}{rrr}672453 & 809306 & 126 \\ 665498 & 816964 & 110 \\ 661212 & 828922 & 125 \\ 657119 & 845547 & 139 \\ 650386 & 854672 & 148 \\ 652830 & 873165 & 112 \\ 652944 & 885966 & 119 \\ 647100 & 897963 & 394 \\ 648447 & 889884 & 146 \\ 640216 & 891443 & 155 \\ 643132 & 885372 & 143 \\ 640102 & 887100 & 131 \\ 645156 & 889109 & 138 \\ 641715 & 883624 & 147 \\ 635376 & 878321 & 154 \\ 629087 & 873872 & 174 \\ 622186 & 873642 & 171 \\ 618466 & 873058 & 179 \\ 618113 & 87808 & 172 \\ 617713 & 880295 & 183 \\ 616051 & 886405 & 162 \\ 610779 & 890838 & 154 \\ 614422 & 905613 & 190 \\ 606258 & 902981 & 187 \\ 603890 & 908680 & 174 \\ 601250 & 916701 & 172 \\ 602521 & 945306 & 174 \\ 602672 & 940484 & 178 \\ 604528 & 938666 & 172 \\ 606420 & 28871 & 168 \\ 671355 & 674614 & 83\end{array}$


North $\quad \underline{m R / y r}$

$0347 \quad$ Boundary TLD Station 347

638710

732411

119

0348 Boundary TLD Station 348

556412

759934

165

0349 Boundary TLD Station 349

557892

833950

174

0350 Boundary TLD Station 350

556098

886398

207

0351

Boundary TLD Station 351

0352

Boundary TLD Station 352

527800

948800

173

0353 Boundary TLD Station 353

558448

944597

113

611581

954202

157

0354 Boundary TLD Station 354

637495

933423

165

0355

Boundary TLD Station 355

635530

904470

114

0356

Boundary TLD Station 356

684659

907578

690664

875015

180

0357

Boundary TLD Station 357

0358

Boundary TLD Station 358

704945

843555

95

0359

Boundary TLD Station 359

709501

789449

88

0360 Boundary TLD Station 360

713111

712618

175

0361

Stake P-77

600660

915405

81

591382

922412

192

585996

915364

200

0363

Stake P-91

574924

921213

188

0364

Stake P-98

586092

953278

177

585663

949445

172

0366

Stake R-26

584602

940864

178

0367

Stake R-18

0368

Stake R-8

584583

929136

170

0369 Stake R-3

583368

923109

197

574296

920114

195

568157

912038

169

563935

909870

170

558798

911202

166

555002

914630

174

551628

919859

183

550159

927574

168

542993

927073

380

557705

927530

175 


\begin{tabular}{llrrr} 
ID & \multicolumn{1}{c}{ Location Name } & East & North & mR/yr \\
0379 & Stake J-6 & & & \\
0380 & Stake A-106 & 568320 & 923335 & 188 \\
0381 & Sandbag Storage Hut & 569434 & 878901 & 177 \\
0600 & RWMS Pit 3 North Side & 656397 & 842004 & 132 \\
0601 & RWMS Pit 3 South Side & 709132 & 767971 & 140 \\
0602 & RWMS Pit 4 North Side & 709072 & 767685 & 132 \\
0603 & RWMS Pit 4 South Side & 707831 & 767324 & 148 \\
0604 & RWMS TRU Pad Northeast & 709024 & 767318 & 176 \\
0605 & RWMS TRU Pad North & 708748 & 766232 & 177 \\
0606 & RWMS TRU Pad Northwest & 708505 & 766244 & 140 \\
0607 & RWMS TRU Pad Southwest & 708481 & 766167 & 124 \\
0608 & RWMS TRU Pad South & 708733 & 766071 & 180 \\
0609 & RVMS TRU Pad Southeast & 708968 & 766010 & 125 \\
0610 & RWMS MSM-I Southeast & 710165 & 771839 & 487 \\
0611 & RWMS MSM-I East & 710144 & 771894 & 1007 \\
0612 & RWMS MSM-I Northeast & 710111 & 771930 & 566 \\
0613 & RWMS MSM-I North-Northeast & 710016 & 771893 & 2659 \\
0614 & RWMS MSM-I North-Northwest & 709934 & 771861 & 874 \\
0615 & RWMS MSM-I Northwest & 709845 & 771827 & 885 \\
0616 & RWMS MSM-I West & 709866 & 771774 & 2240 \\
0617 & RWMS MSM-I Southwest & 709883 & 771729 & 935 \\
0618 & RWMS MSM-I South-Southwest & 709976 & 771765 & 938 \\
0619 & RWMS MSM-I South-Southeast & 710068 & 771801 & 1434 \\
0620 & RWMS MSM-2 Northeast & 709852 & 771577 & 1414 \\
0621 & RWMS MSM-2 North & 709792 & 771544 & 2279 \\
0622 & RWMS MSM-2 Northwest & 709734 & 771513 & 1388 \\
0623 & RWMS MSM-2 West & 709767 & 771454 & 2939 \\
0624 & RWMS MSM-2 Southwest & 709801 & 771391 & 1140 \\
0625 & RWMS MSM-2 South & 709861 & 771424 & 3791 \\
0627 & RWMS MSM-2 Southeast & 709919 & 771455 & 1789 \\
0627 & RWMS MSM-2 East & 709886 & 771515 & 5581
\end{tabular}


ID

Location Name

0628

0629

0630

0631

0632
AH/AT North

AH/AT South

AH/AT East

AH/AT West

AH/AT South Gate
East North mR/yr

686972

686888

686907

686864

687139
$838328 \quad 151$

$835727 \quad 227$

$836167 \quad 148$

$837751 \quad 150$

$837465 \quad 152$ 


$$
33
$$




\section{DISTRIBUTION LIST}

\section{U.S. Department of Energy}

Office of Scientific and Technical Information, Oak Ridge, TN (2)

U.S. Department of Energy, Nevada Field Office

W. D. Wiggins, ERWM, Las Vegas, NV (25)

Technical Library (2)

Reynolds Electrical \& Engineering Co.. Inc.

H. W. Dicíson, Las Vegas, NV (1)

L. S. Sygitowicz, Mercury, NV (1)

F. D. Ferate, II, Mercury, NV (1)

R. R. Kinnison, Las Vegas, NV (12)

Information Products Section, Las Vegas, NV (2) 
